\title{
Mixed convection flow in a vertical channel with temperature dependent viscosity and flow reversal: An exact solution
}

\author{
Basant K. Jha, Michael O. Oni* \\ Ahmadu Bello University, Zaria 810222, Nigeria \\ Corresponding Author Email: michaeloni29@yahoo.com
}

https://doi.org/10.18280/ijht.360225

Received: 23 October 2017

Accepted: 3 May 2018

\section{Keywords:}

mixed convection,vertical channel, temperature dependent viscosity,

flow reversal, exact solution

\begin{abstract}
An exact solution of steady fully developed mixed convection flow of viscous, incompressible fluid in a vertical channel having temperature dependent viscosity with asymmetric wall heating is obtained in this article. The Reynold model is used to capture the variation of viscosity as an exponential function of temperature and the governing equations are solved analytically. The solutions obtained are graphical represented and the effects of viscosity variation parameter, mixed convection parameter and wall temperature difference ratio on fluid velocity and skin-friction are investigated. In addition, the condition for occurrence of reverse flow at the channel walls is also established. During the course of numerical computation, it is found that an increase in viscosity variation parameter increases both fluid velocity as well as skin-friction at the heated wall. Furthermore,] the magnitude of flow reversal increases with increase in viscosity variation parameter around the cold region while the role of wall temperature difference ratio is to minimize the occurrence of reverse flow.
\end{abstract}

\section{INTRODUCTION}

The study of combined natural and forced convection flow in a parallel-plate vertical channel appears in many practical engineering applications, including heat exchangers, chemical processing tools, geothermal energy mining, food processing, molding and fusing of manufacturing process, dispersion of chemical contaminants in various processes and in the chemical industry, transport system for heated or cooled fluids and many others [1]. Theoretical study of such kind of fluid flow is very significant in improvement of these applications. An analytical solution for laminar mixed convection in a channel with a uniform wall heat flux heated fluid and downward flow is presented by Lavine [2]. The earliest analyses of laminar and fully developed mixed convection in the parallel-plate vertical channel with uniform temperatures at the boundaries can be found in the work of Tao [3]. Hamadah and Wirtz [4] showed that for mixed convection in a vertical channel subject to asymmetric heating conditions, the buoyancy force enhances heat transfer near the hotter wall and causes a flow reversal near the cooler wall. Barletta [5] presented a perturbation-based method for analyzing the effects of viscous dissipation in laminar combined forced and free convection flows in a parallel-plate vertical channel. Lin et al. [6] studied mixed convection from an isothermal horizontal plate moving in parallel or reversely to a free stream. In their work, they discuss the effect of buoyancy force.

In real life, it is known that physical property such as viscosity of fluid changes significantly with temperature. For gases, viscosity increases with increase in temperature, while for liquid, it decreases as temperature increases. However, most of the existing analytical studies assume constant fluid viscosity. Accurate prediction for flow formation and heat transfer can be achieved by considering variation of physical properties with temperature [7-8] especially fluid viscosity. Shome and Jensen [9] studied a simultaneously developing laminar flow and heat transfer, with variable viscosity. The method utilized in their article is a general purpose commercial program, based on the finite volume method. Jha and Aina [7] investigated steady fully developed natural convection flow in a vertical annular microchannel having temperature dependent viscosity and concluded that increase in viscosity variation increases velocity of the fluid and skin-friction at the surfaces of the cylinder. Other relevant research works on mixed convection flow in a channel with variable viscosity can be seen in [10-20]

Reverse flow is a situation where fluid flows in opposite direction to the direction of flow. This phenomena is common in medical field where some illness are caused as a result of opposite flow of blood or water molecules [21-22]. The analysis of flow reversal in mixed convection flow has receive great attention in the recent past. Sparrow et al. [23] presented an experimental occurrence of reverse flow. Ostrach [24], Lietzke [25], Cebeci et al. [26] provided an approximation analysis for parallel-streamline, bidirectional shear flow in mixed convection. Aung and Worku [27] and [28] presented analytical solution for mixed convection flow in a vertical channel with asymmetric heating of the walls for developing and fully developed flow respectively. In these works, they offered conditions under which flow reversal arises. Other related literatures are [29-32] where temperature dependent viscosity effects on flow formation are established. 
The investigation of exact solution plays a vital role in checking the accuracy, continuity and convergence of various numerical computation methods. Exact solutions are therefore significant in flow formation and heat transfer with temperature dependent viscosity.

The purpose of this work is to present an exact solution of steady fully developed mixed convection flow of fluid having temperature dependent viscosity in a vertical channel with asymmetric heating of the walls. The mathematical model employed herein represents a generalization of the work discussed in [28] to include a more realistic physical problem (temperature dependent viscosity). Analytical solutions of the momentum and energy equations are presented and the condition for occurrence of reverse flow is established. These solutions generally deserve great attention, since it allow one to gain a deeper knowledge of the underlying physical situation. Moreover, it is hoped that the results obtained will not only provide useful information for industrial applications, but also serve as an improvement to the previous studies.

\section{MATHEMATICAL ANALYSIS}

Consider a steady fully developed mixed convection flow in a vertical channel with temperature dependent viscosity subjected to asymmetric heating of the channel walls. The fluid flow is induced by combined effect of constant pressure gradient (forced convection) and temperature difference of the walls and the fluid (Natural convection). A schematic geometry of the problem under investigation is shown in Fig. 1 , where $x$-axis is parallel to the gravitational acceleration $g$ but in the opposite direction, while $y-$ axis is the flow direction. The wall $(y=H)$ is assume to be heated with temperature $\left(T_{2}\right)$ greater than the surrounding fluids having temperture $\left(T_{0}\right)$ and the wall $(y=0)$ is heated to a temperature $\left(T_{1}\right)$.

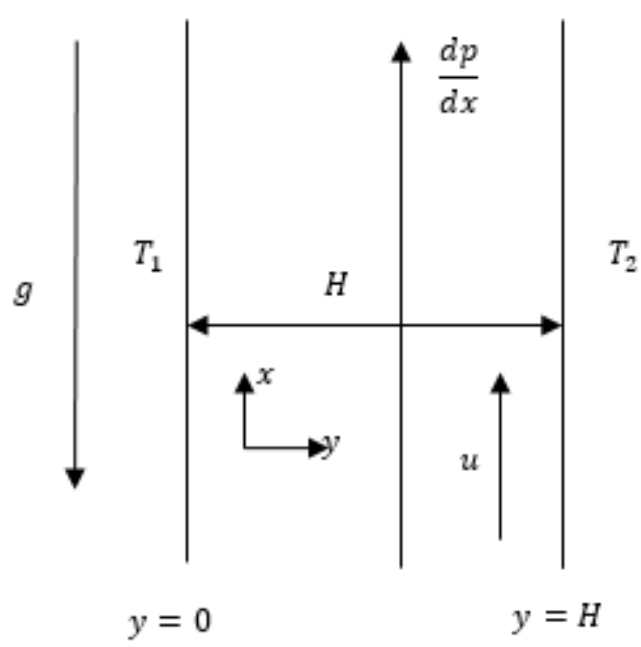

Figure 1. Schematic diagram of the problem

Using Boussinesq's approximation and considering thermally and hydrodynamically fully developed region of flow formation with temperature dependent viscosity and constantly applied pressure gradient, in the absence of viscous dissipation, the governing momentum and energy equations, describing the present physical situation can be written in dimensional form as follows:

Conservation of momentum $\frac{d}{d y}\left(\mu \frac{d u}{d y}\right)+g \rho_{0} \beta_{0}\left(T-T_{0}\right)=\frac{d p}{d x}$

\section{Conservation of energy}

$\frac{d^{2} T}{d y^{2}}=0$

The boundary conditions for the velocity and temperature field in dimensional form are as follows:

$u=0, \quad T=T_{1}$

$u=0, \quad T=T_{2}$

$$
\text { at } \quad y=0
$$$$
\text { at } \quad y=H
$$

The mathematical model used in the present work to capture the viscosity variation with temperature is the exponential model proposed by Reynolds [33, 34]

$\mu=\mu_{0} \exp \left[-b\left(T-T_{0}\right)\right]$

where $\mu_{0}$ is the viscosity when temperature is $T_{0}$ while the coefficient $b$ determines the strength of dependency between the viscosity $(\mu)$ and temperature $(T)$.

Introducing the following dimensionless quantities [28] in Equations (1)- (4),

$$
\begin{gathered}
U=\frac{u}{u^{\prime}}, \theta=\frac{\left(T-T_{0}\right)}{\left(T_{2}-T_{0}\right)}, Y=\frac{y}{H}, B=b\left(T_{1}-T_{0}\right), P=\frac{p}{\rho u^{\prime 2}}, \\
\sigma_{T}=\frac{\left(T_{1}-T_{0}\right)}{\left(T_{2}-T_{0}\right)}, \quad G r=\frac{g \beta\left(T_{2}-T_{0}\right) H^{3}}{v^{2}}, R e=\frac{u^{\prime} H}{v}, \\
X=\frac{x}{H}
\end{gathered}
$$

Using equation (5), equations (1 - 4) can be written in dimensionless form as:

$\frac{d}{d Y}\left(\exp [-B \theta] \frac{d U}{d Y}\right)=-\frac{G r}{R e} \theta+\alpha$

$\frac{d^{2} \theta}{d Y^{2}}=0$

subject to the following dimensionless boundary conditions

$$
\begin{aligned}
& U=0, \quad \theta=\sigma_{T} \quad \text { at } \quad Y=0 \\
& U=0, \quad \theta=1 \quad \text { at } \quad Y=1
\end{aligned}
$$

All physical quantities used in the above equations are defined in the nomenclature. where $\sigma_{T}$ measures the degree of asymmetric heating.

Integrating Eq. (7) and applying boundary conditions (8) gives:

$\theta(Y)=\left(1-\sigma_{T}\right) Y+\sigma_{T}$

The expression for temperature distribution in Eq. (9) is exactly the same as those obtained by Aung and Worku [28]. Substituting Eq. (9) into the moment momentum Eq. (1) and solving it using the boundary condition (8) gives:

$$
\begin{aligned}
& U(Y)=-\frac{G r}{R e}\left[\frac{\left(1-\sigma_{T}\right)}{2} I_{2}(Y)+\sigma_{T} I_{1}(Y)\right] \exp (B \theta)+ \\
& \alpha I_{1}(Y) \exp (B \theta)-\frac{C_{1}}{a_{1}} \exp (B \theta)+C_{2}
\end{aligned}
$$

where $I_{1}(Y)$ and $I_{2}(Y)$ are variables and $C_{1}, C_{2}$ are constants defined in appendix. 
For purely forced convection flow $\left(\frac{G r}{R e}=0\right)$, Eq. (10) becomes:

$U(Y)=\left[\frac{I_{1}(Y)}{a_{20}}-\frac{a_{12}}{a_{20}}\right] \exp (B \theta)+\frac{a_{14}}{a_{20}}$

In the case of symmetric heating of channel walls $\left(\sigma_{T}=1\right)$, the velocity profile becomes:

$U(Y)=\exp (B)\left[\frac{\alpha_{1}}{2} Y(Y-1)+\frac{G r}{2 R e} Y(1-Y)\right]$

where $\alpha$ and $\alpha_{1}$ are pressure gradients obtained for asymmetric and symmetric heating of channel walls respectively and these pressures are obtained using the conservation law;

$\int_{0}^{1} U(Y) d Y=\int_{0}^{1} d Y$

On solving for the pressure gradient in equation (13), we obtained;

$\alpha=\frac{1}{a_{20}}-\frac{G r}{R e} a_{21}$

$\alpha_{1}=\frac{G r}{R e}-12 \exp (-B)$

The parameter of interest is critical values of mixed convection parameter $\left(\frac{G r}{R e}\right)$ and the skin-frictions $(\tau)$ at the channel walls. The temperature solution as well as rate of heat transfer is exactly the same as discussed by Aung and Worku [28] and hence not considered in the present article.

It is of great importance to know the values of $\left(\frac{G r}{R e}\right)$ for which the velocity changes direction (reverse flow). Most Engineering and medical systems are designed in such a way to avoid reverse flow.

The critical values of $\left(\frac{G r}{R e}\right)$ can be obtained from the turning point of the velocity:

$\left.\frac{d U}{d Y}\right|_{Y=0}=0 \quad$ and $\left.\quad \frac{d U}{d Y}\right|_{Y=1}=0$

$\left.\frac{G r}{R e}\right|_{Y=0}=\frac{a_{12}}{a_{20}\left[a_{12} a_{21}-a_{11}\right]} \quad$ and $\left.\quad \frac{G r}{R e}\right|_{Y=1}=\frac{\left(1+a_{12}\right)}{a_{20} a_{22}}$

The skin-friction $(\tau)$ at the channel walls is defined as the drag force by which the fluid hits the surfaces of the channel walls and are given as follows:

$$
\begin{aligned}
& \tau_{0}=\left.\mu(T) \frac{d U}{d Y}\right|_{Y=0} \\
& \tau_{0}=\left.\exp (-B \theta) \frac{d U}{d Y}\right|_{Y=0} \\
& \tau_{0}=F_{1}+F_{2} C_{1} \\
& \tau_{1}=\left.\mu(T) \frac{d U}{d Y}\right|_{Y=1} \\
& \tau_{1}=\left.\exp (-B \theta) \frac{d U}{d Y}\right|_{Y=1} \\
& \tau_{1}=F_{3}+F_{2} C_{1}
\end{aligned}
$$

where $a_{1}, a_{2} a_{3}, \ldots, F_{1}, F_{2}, F_{3}$ are constants defined in appendix

\section{RESULTS AND DISCUSSION}

The exact solutions obtained in Eqs. (10-23) is seen to be controlled by mixed convection parameter $\left(\frac{G r}{R e}\right)$, wall temperature difference ratio $\left(\sigma_{T}\right)$, viscosity variation parameter $(B)$ and constant pressure gradient $(\alpha)$. In order to have a deeper understanding of the present work, MATLAB program is written to compute and generate line graphs for velocity, skin-friction at both walls and pressure gradient for different values of governing parameters. The $\left(\frac{G r}{R e}\right)$ represents a measure of the effects of the buoyancy in comparison with that of inertia of the external force on fluid flow. Outside the mixed convection region, either the pure forced or the free convection analysis can be used to describe accurately the flow or the temperature field. Forced convection is the dominant mode of transport when $\left(\frac{G r}{R e} \rightarrow 0\right)$, whereas, free convection is the dominant mode when $\left(\frac{G r}{R e} \rightarrow \infty\right)$. For the numerical validation of our results, we have chosen physically meaningful values of the parameters entering the problem. Mixed convection parameter $\left(-500 \leq\left(\frac{G r}{R e}\right) \leq 500\right)$ so that it can capture the occurrence of reverse flow, viscosity variation parameter $(-1.5 \leq B \leq 1.5)$ and wall temperature difference ratio as $\left(0 \leq \sigma_{T}<1\right)$.

Table 1 presents the critical values of $\left(\frac{G r}{R e}\right)$ for different values of wall temperature difference ratio and viscosity variation parameter. It is observed that the critical $\left(\frac{G r}{R e}\right)$ decreases with increase in viscosity variation parameter but increases with increase in wall temperature difference ratio. It is interesting to note from the depicted graphs that, reverse flow occur for mixed convection parameter $\left(\frac{G r}{R e}\right)$ outer the range of values given in this Table 1 . Table 2 on the other hand gives numerical comparison between the velocity profiles of present work and [28]. As expected, it is noticed that as viscosity variation parameter tends to zero $(B \rightarrow 0)$, fluid velocity corresponds to the findings of [28].

Figure 2 depicts combined effect of mixed convection parameter $\left(\frac{G r}{R e}\right)$ and viscosity variation parameter $(B)$ on velocity of the fluid at for the case of asymmetric wall heating $\left(\sigma_{T}=0\right)$. It is observed that fluid velocity decreases with increase in viscosity variation parameter as well as mixed convection parameter at the region closer to the cold wall while the reversed case is noticed at the region closer to the heated wall. As expected, point of inflexion is seen around the center of the channel, whose location in the channel is dependent on viscosity variation parameter. In addition, the minimum and maximum magnitude of velocity is observed at the region closed to the cold and heated wall respectively which is strongly dependent on mixed convection parameter $\left(\frac{G r}{R e}\right)$. This is true since less dense fluid moves freely than denser ones.

Figure 3 shows velocity profile varying wall temperature difference ratio and viscosity variation parameter at constant mixed convection parameter. It is evidence that as wall temperature difference ratio $\left(\sigma_{T}\right)$ and viscosity variation parameter increases, fluid velocity near the wall $(Y=0)$ increases and decreases respectively. The effect of wall 
temperature difference ratio is to eliminate the occurrence of reverse flow at the wall $(Y=0)$. The reversed trend is noticed for velocity profile close to the heated wall.

Table 1. Critical values of $\left(\frac{G r}{R e}\right)$ for different values of wall temperature difference ratio and viscosity variation parameter

\begin{tabular}{|c|c|c|c|}
\hline$\sigma_{\mathrm{T}}$ & $\bar{B}$ & $G r$ & $G r$ \\
\hline & & $\left.\overline{\operatorname{Re}}\right|_{Y=0}$ & $\left.\overline{\operatorname{Re}}\right|_{Y=1}$ \\
\hline \multirow{4}{*}{0.0} & -1.5 & 159.9254 & 143.7272 \\
\hline & 0.001 & 73.1316 & 70.8331 \\
\hline & 0.5 & 55.1088 & 56.9915 \\
\hline & 1.5 & 32.0699 & 35.6842 \\
\hline \multirow{4}{*}{0.2} & -1.5 & 230.0338 & 211.6011 \\
\hline & 0.001 & 86.5221 & 93.6526 \\
\hline & 0.5 & 65.7627 & 67.5489 \\
\hline & 1.5 & 34.9774 & 38.0243 \\
\hline \multirow{4}{*}{0.4} & -1.5 & 352.9748 & 331.9203 \\
\hline & 0.001 & 119.9384 & 119.8921 \\
\hline & 0.5 & 83.7020 & 85.3977 \\
\hline & 1.5 & 40.6458 & 43.2240 \\
\hline \multirow{4}{*}{0.6} & -1.5 & 609.3373 & 585.1824 \\
\hline & 0.001 & 178.5456 & 178.5858 \\
\hline & 0.5 & 119.8442 & 121.4549 \\
\hline & 1.5 & 53.0865 & 55.2778 \\
\hline \multirow{4}{*}{0.8} & -1.5 & 1402.4 & 1374.5 \\
\hline & 0.001 & 357.2031 & 356.3468 \\
\hline & 0.5 & 228.7769 & 230.3077 \\
\hline & 1.5 & 92.3767 & 94.2482 \\
\hline
\end{tabular}

Table 2: Numerical comparison of present work velocity with those obtained by Aung and Worku [28]

\begin{tabular}{|c|c|c|c|c|}
\hline \multirow[t]{2}{*}{$Y$} & \multirow{2}{*}{$\frac{G r}{R e}$} & \multirow[t]{2}{*}{$\sigma_{\mathrm{T}}$} & \multicolumn{2}{|c|}{ Velocity profiles } \\
\hline & & & $\begin{array}{c}\text { Aung and Worku } \\
{[28]}\end{array}$ & $\operatorname{Present}(B \rightarrow 0)$ \\
\hline \multirow{7}{*}{0.2} & \multirow{4}{*}{0} & 0 & 0.9600 & 0.9599 \\
\hline & & 0.4 & 0.9600 & 0.9599 \\
\hline & & 0.8 & 0.9600 & 0.9599 \\
\hline & & & & \\
\hline & \multirow{3}{*}{100} & 0 & 0.1600 & 0.1599 \\
\hline & & 0.4 & 0.4800 & 0.4798 \\
\hline & & 0.8 & 0.8000 & 0.7993 \\
\hline \multirow{7}{*}{0.4} & \multirow{4}{*}{0} & 0 & 1.4400 & 1.4400 \\
\hline & & 0.4 & 1.4400 & 1.4401 \\
\hline & & 0.8 & 1.4400 & 1.4398 \\
\hline & & & & \\
\hline & \multirow{3}{*}{100} & 0 & 1.0400 & 1.0404 \\
\hline & & 0.4 & 1.2000 & 1.1998 \\
\hline & & 0.8 & 1.3600 & 1.3594 \\
\hline \multirow{7}{*}{0.6} & \multirow{3}{*}{0} & 0 & 1.4400 & 1.4399 \\
\hline & & 0.4 & 1.4400 & 1.4401 \\
\hline & & 0.8 & 1.4400 & 1.4400 \\
\hline & \multirow{4}{*}{100} & & & \\
\hline & & 0 & 1.8400 & 1.8400 \\
\hline & & 0.4 & 1.6800 & 1.6801 \\
\hline & & 0.8 & 1.5200 & 1.5198 \\
\hline \multirow{6}{*}{0.8} & \multirow{3}{*}{0} & 0 & 0.9600 & 0.9601 \\
\hline & & 0.4 & 0.9600 & 0.9601 \\
\hline & & 0.8 & 0.9600 & 0.9601 \\
\hline & \multirow{3}{*}{100} & 0 & 17600 & 17601 \\
\hline & & 0.4 & 1.4400 & 1.4404 \\
\hline & & 0.8 & 1.2000 & 1.1999 \\
\hline
\end{tabular}
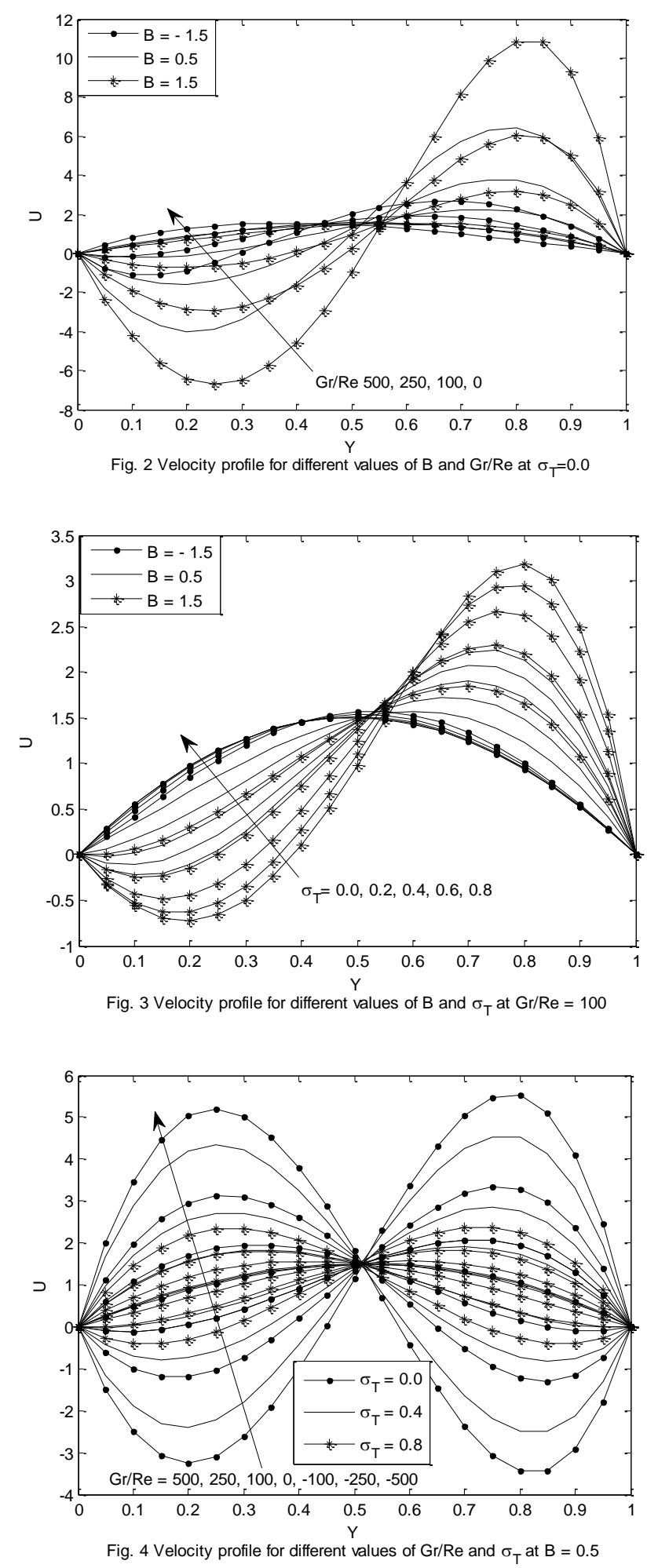

Figure 4 reveals the influence of mixed convection parameter and wall temperature difference ratio on velocity profile at fixed value of viscosity variation parameter $(B=0.5)$. It is observed that fluid velocity decreases and increases with increase in mixed convection parameter and wall temperature difference ratio respectively at the wall with variable temperature. The reversed case is noticed at region closer to the heated wall. 

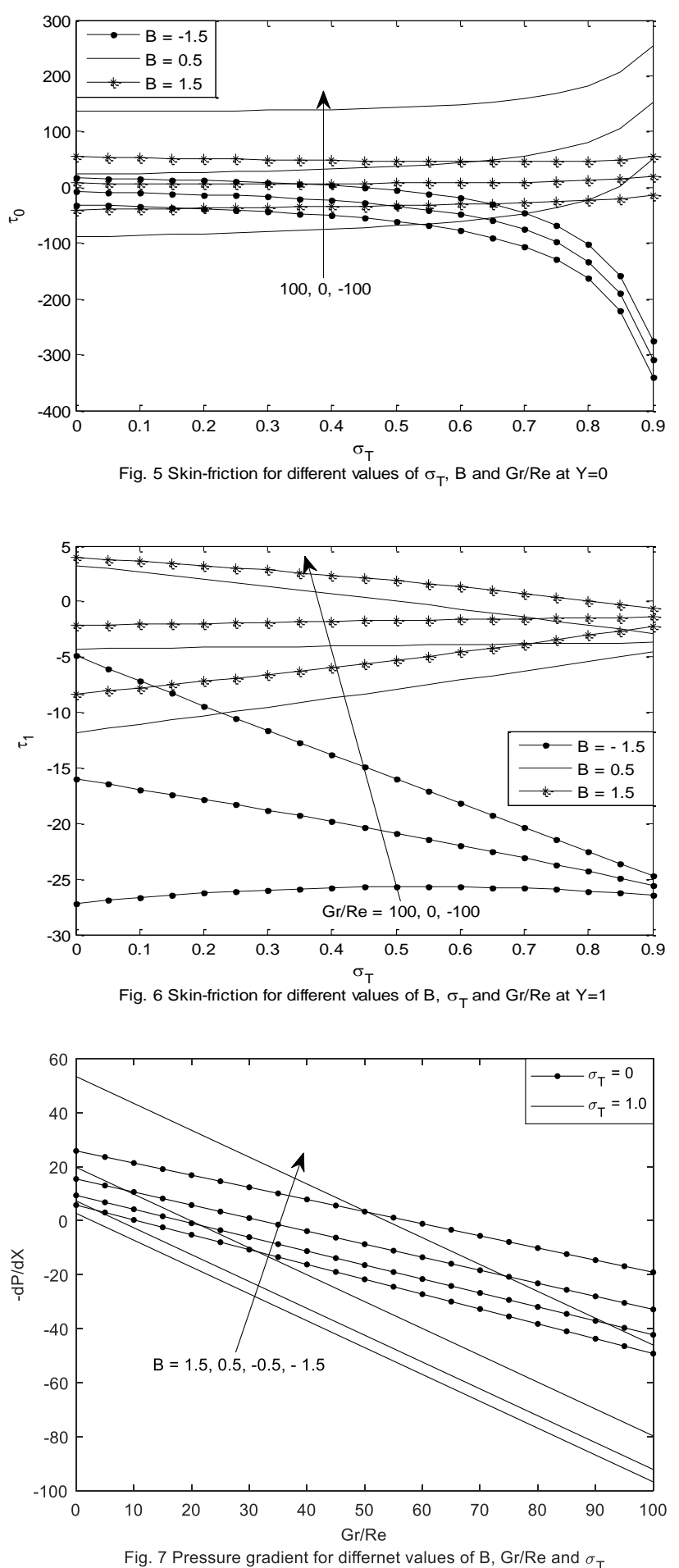

Figure 5 illustrates the effect of viscosity variation parameter, mixed convection parameter and wall temperature difference ratio on skin-friction at the channel wall $Y=0$. It is noticed that viscosity variation parameter as well as wall temperature difference ratio enhances skin-friction for positive values of $B$ and has an opposing effect for negative values of $B$. Figure 6 on the other hand exhibits the effect of these governing parameter on the skin-friction at the heated wall $(Y=1)$. It is easy to observe that skin-friction increases with increase in $B$. From Figures 5 and 6 , the role of mixed convection parameter is to decrease skin-friction at both walls. This can be attributed to the fact that increase in mixed convection parameter increases the buoyancy force which in turn reduces the drag effect at the wall surfaces.
Figure 7 plots the gradient of pressure parameter $(\alpha)$ as a function $\left(\frac{G r}{R e}\right), B$ and $\left(\sigma_{T}\right)$. It is realized from this figure that that pressure gradient decreases with increase in mixed convection parameter $\left(\frac{G r}{R e}\right)$ as well as viscosity variation ratio (B) for all $\left(\sigma_{T}\right)$. This could be attributed to the fact that the pressure is applied in perpendicular direction to buoyancy and hence results in adverse pressure gradient.

\section{CONCLUSIONS}

An exact solution of steady fully developed mixed convection flow in a vertical channel with temperature dependent viscosity and flow reversal is presented in this article. The role of viscosity variation parameter, mixed convection parameter and wall temperature difference ratio on fluid velocity and skin-friction is investigated. This study agrees with the findings of Aung and Worku [27] in the absence of viscosity variation parameter $(B \rightarrow 0)$. The main conclusions of the present work are:

1. Viscosity variation parameter and mixed convection parameter increases the velocity along the heated wall while the reversed trend is found along the cooled wall.

2. Magnitude of reverse flow increases with increase in viscosity variation parameter $(B)$ at the cold wall while the opposite result is noticed at the heated wall.

3. Wall temperature difference ratio enhances fluid velocity at the region closer to the cold wall while the contrary result occurs at the region closer to the heated wall.

4 Reverse flow occurrence at the channel walls can be minimized by increasing wall temperature difference ratio.

5. Skin-friction at the heated wall increases with increase in viscosity variation parameter and wall temperature difference ratio but decreases with increase in mixed convection parameter .

6. The position of inflexion point in velocity profile is dependent on viscosity variation parameter.

\section{REFERENCES}

[1] Lavine AS. (1988). Analysis of fully developed opposing mixed convection between inclined parallel plates. Warme-und Stoffubertragung. Springer, Berlin 23: 249257.

[2] Lavine AS. (1993). On the linear stability of mixed and free convection between inclined parallel plates with fixed heat flux boundary conditions. Int. J. Heat Mass Transfer 1373-1387.

[3] Tao LN. (1991). On combined free and forced convection in channels. ASME Journal of Heat Transfer 82: $233-8$.

[4] Hamadah TT, Wirtz RA. (1991). Analysis of laminar fully developed mixed convection in a vertical channel with opposing buoyancy. ASME Journal of Heat Transfer 113: 507-10.

[5] Barletta A. (1998). Laminar mixed convection with viscous dissipation in a vertical channel. Int. J. Heat Mass Transfer 41: 3501-3513.

[6] Lin HT, Wu KY, Hoh HL. (1993). Mixed convection from an isothermal horizontal plate moving in parallel or reversely to a free stream. Internat. J. Heat Mass Transfer 36:3547-3554. 
[7] Herwig H, Wicken G. (1986). The effect of variable properties on laminar boundary layer flow. Warme-und Stof-Fubertrag 20: 47-57.

[8] Jha BK, Babatunde A. (2016). Steady fully developed natural convection flow in a vertical annular microchannel having temperature dependent viscosity: An exact solution. Alexandria Eng. J. 55(2): 951-958. http://dx.doi.org/10.1016/j.aej.2016.02.023

[9] Shome B, Jensen M.K. (1995). Mixed convection laminar flow and heat transfer of liquids in isothermal horizontal circular ducts. Int. J. Heat Mass Transfer 38: 1945-1956.

[10] Makinde OD, Chinyoka T. (2012). Analysis of unsteady flow of a variable viscosity reactive fluid in a slit with wall suction or injection J. Petrol. Sci. Eng. 94(95): 1-11.

[11] Hossain MA, Munir MS. (2000). Mixed convection flow from a vertical flat plate with temperature dependent viscosity. Internat. J. Thermal.Sci. 39: 173-183.

[12] Klemp K, Herwig H, Selmann M. (1990). Entrance flow in channel with temperature dependent viscosity including viscous dissipation effects. Int. Proceedings of the Third International Congress of Fluid Mechanics. Cairo, Egypt 3: 1257-1266.

[13] Kumari M. (2001). Variable viscosity effects on free and mixed convection boundary-layer flow from a horizontal surface in a saturated porous medium - variable heat flux. Mech. Res. Commun. 28: 339-348.

[14] Umavathi JC, Ojjela O. (2015). Effect of variable viscosity on free convection in a vertical rectangular duct. Int. J. Heat Mass Transf. 84: 1-15.

[15] Hady FM, Bakier AY, Gorla RSR. (1996). Mixed convection boundary layer flow on a continuous flat plate with variable viscosity. Heat Mass Transf. 31: 169-172.

[16] Mahmud MAA. (2007). A note on variable viscosity and chemical reaction effects on mixed convection heat and mass transfer along a semi-infinite vertical plate. Math. Probab. Eng. http://dx.doi.org/1155/2007/41323

[17] Pop I, Gorla RSR, Rashidi M. (1992). The effect of variable viscosity on flow and heat transfer to a continuous moving flat plate. Internat. J. Engrg. Sci. 30 (1): 1-6.

[18] Elbashbeshy EMA, Bazid MA.A. (2000). The effect of temperature dependent viscosity on heat transfer over a continuous moving surface. J. Phys. D: Appl. Phys. 33: 2716-2721.

[19] Ling JX, Dybbs A. (1987). Forced convection over a flat plate submersed in a porous medium: Variable viscosity case, ASME Paper 87-WA/HT-23. ASME Winter Annual Meeting, Boston, Massachusetts, pp. 13-18.

[20] Jha BK, Oni MO, Aina B. (2016). Steady fully developed mixed convection flow in a vertical micro-concentricannulus with heat generating/absorbing fluid: an exact solution. Ain Shams Engineering Journal http://dx.doi.org/ 10.1016/j.asej.2016.08.005

[21] Liepsch DW. (1990). Effect of blood flow parameters on flow patterns at arterial bifurcations- studies in models. In blood flow in large arteries: Applications to atherogenesis and clinical medicine (ed. Liepsch D.W.), pp. 63-76. Basel, Switzerland: Karger.

[22] Kazakidi A, Plata AM, Sherwin SJ, Weinberg PD. (2011). Effect of reverse flow on the pattern of wall shear stress near arterial branches. J. R. Soc. Interface 8: 1594-1603. http://dx.doi.org/10.1098/rsif.2011.0108

[23] Sparrow EM., Chrysler GM, Azevedo LF. (1984). Observed flow reversal and measured-predicted Nusselt numbers for natural convection in one-sided heated vertical channel. ASME Journal of Heat Transfer 106(2): 325-332.

[24] Ostrach S. (1954). Combined natural and forced convection laminar flow heat transfer of fluids with and without heat sources in channels with nearly varying wall temperatures. NACA TN 3141.

[25] Leitzke AF. (1954). Theoretical and experimental investigation of heat transfer by laminar natural convection between parallel plates. NACA report 1223 .

[26] Cebeci T, Khattab AA, LaMont R. (1982). Combined natural and forced convection in vertical ducts. Heat Transfer 82 , Proceedings of $7^{\text {th }}$ international Heat Transfer Conference, Munich, West Germany 2: 419-424.

[27] Aung W, Worku G. (1986). Developing flow and flow reversal in mixed convection in a vertical channel with asymmetric wall temperatures. J. Heat Transfer 108: 485-488.

[28] Aung W, Worku G. (1986). Theory of fully developed, combined convection including flow reversal. J. Heat Transfer 108: 299-307.

[29] Prasad KV, Vajravelu K, Vaidya H, Raju B.T. (2015). Heat transfer in a non-newtonian nanofluid film over a stretching surface. Journal of Nanofluids 4(4): 536547(12).

[30] Oni MO. (2017). Combined effect source, porosity and thermal radiation on mixed convection flow in a vertical annulus: An exact solution. Engineering Science and Technology, an International Journal 20: 518-527.

[31] Prasad KV, Mallikarjun P, Vaidya H. (2017). Mixed convective fully developed flow in a vertical channel in the presence of thermal radiation and viscous dissipation. Int. J. of Applied Mechanics and Engineering 22(1): 123144. http://dx.doi.org/10.1515/ijame-2017

[32] Prasad KV, Vaidya H, Vajravelu K. (2015). MHD mixed convection heat transfer in a vertical channel with temperature-dependent transport properties. Journal of Applied Fluid Mechanics 8(4): 693-701.

[33] Reynolds O. (1886). Phil Trans Royal. Soc. London, pp. 177: 157.

[34] Syeda HT, Shohel M. (2002). Entropy generation in a vertical concentric channel with temperature dependent viscosity. Int. Commun. Heat Mass Transf. 29: 907-918.

\section{NOMENCLATURE}

$B \quad$ viscosity variation parameter

$g \quad$ acceleration due to gravity $\left(m s^{-2}\right)$

Gr Grashof number

$H \quad$ spacing between the duct walls $(m)$

$p \quad$ pressure $(\mathrm{Pa})$

$P \quad$ dimensionless pressure

$\sigma_{T} \quad$ wall temperature difference ratio

Re Reynolds number

$T$ temperature $(K)$

$u^{\prime} \quad$ axial velocity $\left(m s^{-1}\right)$

$U \quad$ dimensionless axial velocity

$x, y \quad$ axial and transverse coordinate respectively $(m)$

$X \quad$ dimensionless axial coordinate

$Y \quad$ dimensionless transverse coordinate

$\alpha \quad$ dimensionless pressure gradient defined in (5)

$\beta \quad$ thermal expansion coefficient $\left(K^{-1}\right)$

$\mu \quad$ dynamic viscosity $(\mathrm{Pas})$ 
$\mu_{0} \quad$ dynamic viscosity at $T=T_{0}$

$v \quad$ kinematic viscosity $\left(m^{2} s^{-1}\right)$

$\rho_{0} \quad$ density $\left(\mathrm{Kgm}^{-3}\right)$

$\theta$ dimensionless temperature

$\tau \quad$ skin-friction

\section{Subscripts}

$0 \quad$ value at duct entrance (i.e at $x=0$ )

1 value on cool wall (i.e at $y=0$ )

2 value on hot wall (i.e at $y=H$ )

$m$ bulk value.

\section{Appendix}

$a_{1}=\left(\sigma_{T}-1\right) B, I_{1}(Y)=-\left(\frac{Y}{a_{1}}+\frac{1}{a_{1}^{2}}\right), \quad I_{2}(Y)=-\left(\frac{Y^{2}}{a_{1}}+\right.$ $\left.\frac{2 Y}{a_{1}{ }^{2}}+\frac{2}{a_{1}{ }^{3}}\right), I_{1}(0)=I_{1}^{*}(0)=-\frac{1}{a_{1}^{2}}, I_{2}(0)=-\frac{2}{a_{1}{ }^{3}}, \quad I_{1}(1)=$ $-\left(\frac{1}{a_{1}}+\frac{1}{a_{1}^{2}}\right) \quad, \quad I_{2}(1)=-\left(\frac{1}{a_{1}}+\frac{2}{a_{1}^{2}}+\frac{2}{a_{1}^{3}}\right), \quad a_{2}=$ $\left[\frac{\left(1-\sigma_{T}\right)}{2} I_{2}(0)+\sigma_{T} I_{1}(0)\right] \exp \left(B \sigma_{T}\right), \quad a_{3}=\left[\frac{\left(1-\sigma_{T}\right)}{2} I_{2}(1)+\right.$ $\left.\sigma_{T} I_{1}(1)\right] \exp (B), \quad a_{4}=I_{1}(0) \exp \left(B \sigma_{T}\right), a_{5}=I_{1}(1) \exp (B)$ $a_{6}=a_{2}-a_{3}, a_{7}=a_{5}-a_{4}, a_{8}=\frac{1}{a_{1}}[\exp (B)-$ $\left.\exp \left(B \sigma_{T}\right)\right] \quad a_{9}=a_{2} \exp (B)-a_{3} \exp \left(B \sigma_{T}\right) \quad, a_{10}=$ $a_{5} \exp \left(B \sigma_{T}\right)-a_{4} \exp (B), \quad, \quad I_{1}^{*}(1)=I_{1}(1) \exp \left(-a_{1}\right)$, $I_{2}^{*}(1)=I_{2}(1) \exp \left(-a_{1}\right), \quad C_{1}=\frac{1}{a_{8}}\left[\frac{G r}{R e} a_{6}+\alpha a_{7}\right]$

$C_{2}=\frac{1}{a_{1} a_{8}}\left[\frac{G r}{R e} a_{9}+\alpha a_{10}\right], \quad a_{15}=-\frac{1}{a_{1}}\left[I_{1}^{*}(1)-I_{1}^{*}(0)\right]+$ $\frac{1}{a_{1}{ }^{3}}\left[\exp \left(-a_{1}\right)-1\right] \quad, \quad a_{17}=\left[\frac{\left(1-\sigma_{T}\right)}{2} a_{16}+\right.$ $\left.r_{T} a_{15}\right] \exp \left(B \sigma_{T}\right), a_{18}=a_{15} \exp \left(B \sigma_{T}\right), a_{16}=-\frac{1}{a_{1}}\left[I_{2}^{*}(1)-\right.$ $\left.I_{2}^{*}(0)\right]-\frac{2}{a_{1}^{2}}\left[I_{1}^{*}(1)-I_{1}^{*}(0)\right]+\frac{2}{a_{1}^{4}}\left[\exp \left(-a_{1}\right)-1\right]$,

$a_{19}=\frac{\left[\exp \left(-a_{1}\right)-1\right] \exp \left(B \sigma_{T}\right)}{a_{1}{ }^{2}}, \quad a_{20}=a_{18}+a_{12} a_{19}+a_{14}$, $a_{21}=\frac{a_{11} a_{19}-a_{17}+a_{13}}{a_{20}}, a_{22}=\frac{\left(\sigma_{T}+1\right)}{2}+a_{21}-a_{11}+a_{12} a_{21}$, $I_{1}^{\prime}(1)=-\frac{1}{a_{1}}, I_{2}^{\prime}(1)=-\left[\frac{2}{a_{1}}+\frac{2}{a_{1}^{2}}\right], F_{1}=$ $-\frac{G r}{R e}\left\{\left[\frac{\left(1-\sigma_{T}\right)}{2} I_{2}(0)+\sigma_{T} I_{1}(1)\right] B\left(1-\sigma_{T}\right)+\left[\frac{\left(1-\sigma_{T}\right)}{2} I_{2}^{\prime}(0)\right]\right\}+$ $\alpha I_{1}(0) B\left(1-\sigma_{T}\right), F_{2}=\frac{B\left(\sigma_{T}-1\right)}{a_{1}}, F_{3}=-\frac{G r}{R e}\left\{\left[\frac{\left(1-\sigma_{T}\right)}{2} I_{2}(1)+\right.\right.$ $\left.\left.\sigma_{T} I_{1}(1)\right] B\left(1-\sigma_{T}\right)+\left[\frac{\left(1-\sigma_{T}\right)}{2} I_{2}^{\prime}(1)+\sigma_{T} I_{1}^{\prime}(1)\right]\right\}+$ $\alpha I_{1}(1) B\left(1-\sigma_{T}\right)+\alpha I_{1}^{\prime}(1)$ 